http://www.ers.usda.gov/briefing/foodsecurity and http://www.fns.usda/fsec. Current research on food security measurement includes measurement of individual food insecurity and hunger, module performance regarding hunger duration and frequency, performance of the module in population subgroups, and the effect of translations on module meaning and performance. National surveys in Canada, New Zealand and Australia also have measured food security. ">

Public Health Nutrition (1368-9800) Volume 5(6A), December 2002, pp 859-864

(C) Nutrition Society 2002

\title{
Measurement of household food security in the USA and other industrialised countries
}

Kathy L Radimer ${ }^{1, C A}$, Kathy L Radimer ${ }^{2}$

${ }^{1}$ Division of Health Examination Statistics, National Center for Health Statistics, Centers for Disease Control and Prevention, Hyattsville, MD 20782, USA

${ }^{2}$ Division of Health Examination Statistics, National Center for Health Statistics, Centers for Disease Control and Prevention, Hyattsville, MD 20782, USA

Abstract Objective: To describe the history and current status of household food security measurement.

Conclusions: In the 1980s evidence of rising levels of hunger was a concern for many, but disputed by some, Americans. Acknowledgement and quantification of hunger was hindered by the lack of an accepted definition and measure of hunger. Qualitative research at Cornell provided a conceptual framework, description, definition and survey items for hunger. The Community Childhood Hunger Identification Project developed an instrument used in numerous communities. Based upon these initiatives, widely accepted definitions of hunger and food insecurity, and the US Household Food Security Module for its measurement, now exist. The module classifies households as food-secure, or food-insecure without hunger or with moderate or severe hunger, and contains household-, adult- and child-referent items. Its inclusion in the Current Population Survey (CPS) since 1995 has yielded annual estimates of food insecurity. A six-item short form of the module, for surveys with severe time constraints, classifies households only as food-secure or food-insecure without or with hunger and contains no child-specific items. Surveys using the 18-item or short-form module can compare results with published national data from the CPS. Information about the module is available at http://www.ers.usda.gov/briefing/foodsecurity and http://www.fns.usda/fsec. Current research on food security measurement includes measurement of individual food insecurity and hunger, module performance regarding hunger duration and frequency, performance of the module in population subgroups, and the effect of translations on module meaning and performance. National surveys in Canada, New Zealand and Australia also have measured food security. 
Keywords: Food insecurity, Food insufficiency, Hunger, Measurement

(C) CAB International, 2002

DOI: $10.1079 / \mathrm{PHN} 2002385$

Hunger emerged as a major issue of social concern in the 1960s. Americans were confronted with the shocking reality of hunger in their own country via a television documentary, 'Hunger in America', and a report by a Citizens' Board of Inquiry, 'Hunger USA', both of which vividly depicted the living conditions, nutritional deficiencies and social plight of hungry Americans. By the end of the decade, a White House Conference on Food, Nutrition and Health had been convened 'to end hunger in America', and President Nixon had requested large increases in funding for federal food programmes, which were expanded or initiated over the following decade 1 .

In the 1980s, community groups and workers in places such as community centres, churches, food pantries and soup kitchens began reporting increases in the numbers of people requesting help with obtaining food. Many began conducting hunger surveys among their clientele and in their communities. National attention was drawn to the issue by such groups as the US Conference of Mayors, the Center on Budget and Policy Priorities, Harvard's School of Public Health and the Food Research and Action Center (FRAC) $\underline{\text { B2B3B4B5B62-7 }}$. There was a general denial of a problem in the executive branch $\underline{8}$, but as public concern grew, President Reagan appointed a Task Force on Food Assistance to investigate allegations of increasing hunger, often attributed to reduced federal assistance and increased poverty 9 .

\section{Lack of consensus in definition and measurement}

A significant hindrance in the development of public policy to address the problem of hunger was lack of consensus about what 'hunger' was and how to measure it. FRAC defined it as 'the physiological and psychological state that comes from not having enough food' - . Reports by the Harvard School of Public Health defined it as 'chronic underconsumption of food and nutrients' $\underline{\mathrm{B} 44,5}$. The President's Task Force on Food Assistance proposed two definitions: 'a condition in which the level of nutrition necessary for good health is not being met because one lacks access to food'; and 'a situation in which someone cannot obtain an adequate amount of food, even if the shortage is not prolonged enough to cause health

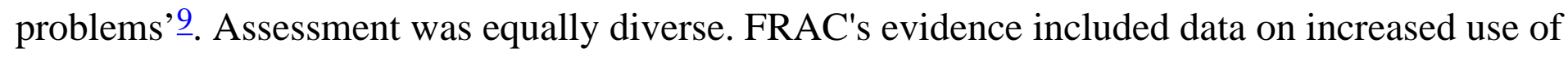
emergency food, increased malnutrition in children and local hunger studies, concluding that the evidence of hunger was compelling and sobering7. Harvard's School of Public Health presented evidence such as case studies of people experiencing food deprivation and findings on emergency food usage. They estimated the extent of hunger using a formula based upon the number of people in or near poverty modified by the number receiving food stamps, concluding that hunger was a problem of epidemic proportions and was growing $\underline{\mathrm{B} 4 \mathrm{~B} 54-6}$. The President's Task Force looked at data including undernutrition, 
the increase in numbers of people in poverty and seeking food assistance, and claims about people running out of food stamps before the end of the month. They concluded that there was no evidence that widespread undernutrition was a major health problem, and that while there was evidence of hunger in the sense that some people had difficulty obtaining adequate access to food, there was no indicator to estimate its extent or whether it was increasing 9 .

\section{Development of a definition and description of hunger}

Research undertaken at Cornell University's Division of Nutritional Sciences for a doctoral dissertation used qualitative research findings to develop a description of hunger with two levels, individual and household, and four components (quantity, quality, psychological and social); and a conceptual framework and definition of hunger (the inability to acquire or consume an adequate quality or sufficient quantity of food in socially acceptable ways, or the uncertainty that one will be able to do so) B10B1110-12. Soon after, the Life Science Research Organization (LSRO), under contract for the American Institute of Nutrition, proposed definitions for food security, food insecurity and hunger, as well as a description of it, incorporating many of the findings from the Cornell research. The LSRO definition and description have been widely adopted. They are:

Food security is defined as access by all people at all times to enough food for an active, healthy life and includes at a minimum: a) the ready availability of nutritionally adequate and safe foods, and $b$ ) the assured ability to acquire acceptable food in socially acceptable ways (e.g. without resorting to emergency food supplies, scavenging, stealing, and other coping strategies). Food insecurity exists whenever the availability of nutritionally adequate and safe foods or the ability to acquire acceptable food in socially acceptable ways is limited or uncertain. Hunger...[is] the uneasy or painful sensation caused by lack of food 13 .

At the individual and household levels, four dimensions (quantity, quality, psychological acceptability, and social acceptability) need to be measured to identify food insecurity. At the individual level, these measures are adequacy of energy intake, adequacy of nutrient intake, feelings of deprivation or restricted choice, and normal meal patterns... At the household level, they are repleteness of household stores, quality and safety of available foods, anxiety about food supplies, and sources of food 13 .

With these definitions, LSRO broadened the term used for this social issue from hunger to food insecurity and limited the term hunger to its physiological meaning.

\section{Development of a measurement instrument}

The Community Childhood Hunger Identification Project (CCHIP) developed an instrument intended to be relatively simple yet scientifically valid for use by communities wanting to measure the prevalence of childhood hunger 14 . Originally piloted in New Haven, CT, a modified survey was undertaken in a variety of communities throughout the USA, under FRAC's sponsorship $\underline{15}$. Additionally, a measurement scale 
for hunger and food insecurity had been developed, analysed and validated at Cornell B10B11B12B1610-12,16,17.

Staff at the Food and Nutrition Service (FNS) of the US Department of Agriculture (USDA) realised the need for a uniform national measure. Together with staff from the National Center for Health Statistics, they convened a panel of expert advisors and compiled a list of 58 questions, mainly based upon those in the CCHIP and the Radimer/Cornell instruments, which were included in a supplement to the 1995 Current Population Survey (CPS) $\underline{\mathrm{B} 1818,19}$.

The items were analysed and, in general, found to be unidimensional despite the various dimensions (described above) being measured. This was attributed to the 'managed' nature of food insecurity in many households, identified in Radimer's research $\underline{B 10 B 11 B 1210-12,20}$, in which household problems are experienced first, then adult's intake quality and quantity as well as children's diet quality are affected, and last, children's intake quantity decreases. Based upon analytical results as well as conceptual considerations, 18 items were selected to form a scale to measure food security. This 'Core Food Security Module', as it was originally called, was designed to measure food insecurity from its least severe aspects to its most severe, in a manner consistent with the definition and description set out by LSRO. The selected items are listed in Table 1. They are listed in order of severity - from least to most severe - based upon the 1995 survey results, which is similar, but not identical to, their order in the module as it is used in a survey. Table 2 portrays the levels and components of food insecurity listed by LSRO, and suggests which of the 18 items in the scale are intended to measure each aspect of food insecurity. Items intended to measure severe levels are noted.

$\underline{\text { TBR1 }}$

18-item Household Food Security Module; items listed in order of severity*

Marginally food-secure $\dagger$

Q1. I/We worried whether my/our food would run out before I/we got money to buy more.

Q2.\$ The food that I/we bought just did not last, and I/we did not have money to get more.

Food-insecure without hunger

Q3. I/we could not afford to eat balanced meals.

Q4

I/we relied on only a few kinds of low-cost foods to feed (my/our child)/the children because I was/we were running out of money to buy food.

Q5.

In the last 12 months, since last (name of month) did you/(you or other adults in your household) ever cut the size of your meals or skip meals because there was not enough money for food?

Q6.

I/we could not feed (my/our child)/the children a balanced meal because I/we could not afford that. 
In the last 12 months, did you ever eat less than you felt you should because there was not enough money to buy food?

\section{Food-insecure with moderate hunger}

Q8. If Q5 is yes: How often did this happen - almost every month, some months but not every month, or in only 1 or 2 months?

Q9.

(My/our child was)/(the children were) not eating enough because I/we just could not afford enough food.

Q10.

In the last 12 months, were you ever hungry but did not eat because you could not afford enough food?

Q11. In the last 12 months, did you lose weight because you did not have enough money for food?

Q12. In the last 12 months, did you ever cut the size of (your child's)/(any children's) meals because there was not enough money for food?

Food-insecure with severe hunger

Q13. In the last 12 months, did you/(you or other adults in your household) ever not eat for a whole
day because there was not enough money for food?

Q14. In the last 12 months, (was your child)/(were the children) ever hungry but you just could not afford more food?

Q15.

If Q13 is yes: How often did this happen (answers as in Q8)?

Q16.

In the last 12 months, did (child's name)/(any of the children) ever skip meals because there was not enough money for food?

Q17.

If Q16 is yes: How often did this happen (answers as in Q8)?

Q18.

In the last 12 months, did (your child)/(any of the children) ever not eat for a whole day because there was not enough money for food?

Components of food security and corresponding module items*

\begin{tabular}{|c|c|c|}
\hline & \multicolumn{2}{|c|}{ Level } \\
\hline Component & Household & Individual \\
\hline \multirow[t]{3}{*}{ Quantity } & Repleteness of household stores & Adequacy of energy intake \\
\hline & Q2 & Adult: Q7 Q10 Q11† Q13† Q15† \\
\hline & & Child: Q9 Q14† Q18† \\
\hline Quality & Quality and safety of available foods & Adequacy of nutrient intake \\
\hline
\end{tabular}




\begin{tabular}{|c|c|c|}
\hline & Q4 & Adult: Q3 \\
\hline & & Child: Q6 \\
\hline Psychological acceptability & Anxiety about food supplies & $\begin{array}{c}\text { Feelings of deprivation and restricted } \\
\text { choice }\end{array}$ \\
\hline & Q1 & Items incorporate this into wording \\
\hline Social acceptability & Sources of food & Normal meal patterns \\
\hline & Q2 (implied) & Adult: Q5 Q8 Q13† Q15† \\
\hline & & Child: Q16† Q17† Q18† \\
\hline
\end{tabular}

\section{Using the US Household Food Security Module}

Detailed information on using the Food Security Module can be found in a new guide, 'Guide to Measuring Household Food Security, Revised 2000', which can be found on the FNS web site (http://www.fns.usda.gov/fsec). Information on the module and people to contact for help with implementing it can also be found at http://www.ers.usda.gov/briefing/foodsecurity.

The module may be preceded by use of one or more screeners. Advice on screening has changed since the original guide was issued, and it is advisable to obtain the more recent guide or talk with USDA/Economic Research Service (ERS) staff about the use of screeners. Different screener procedures may slightly affect prevalence estimates derived from the module. In general, screeners have been based upon income (if available), screening out households at either twice the poverty level or with an income $>\$ 50$ 000, and/or the household's response to the USDA food sufficiency question, described below. Currently, the National Health and Nutrition Examination Survey (NHANES) is using a screen of four times the poverty level. In addition, there are two screens within the module, and households responding negatively to all previous items are not asked subsequent items, since they are ordered in approximate severity order. Items about children are only asked for households with children.

Use of screens substantially reduces the average time per respondent to administer the core module. In a typical US population, it is estimated that, on average, these items will take slightly less than a minute and a half to administer, with a maximum of 3 minutes for households with children answering all items.

Scoring of the scale is depicted in Table 3, denoting what level of food security is associated with various numbers of positive responses. There is an underlying assumption that households will respond to questions in the predicted order from least to most severe (as ordered in Table 1). Although this may not always occur, scoring assumes this overall sequencing, and food security level corresponds to the total number of positive responses, rather than the particular item responses. Previously, a household responding positively to $0-2$ items was classified as food-secure. In the new guide, households affirming no items are classified as food-secure, and those affirming 1 or 2 items are now classified as 'at risk' of 
being food-insecure or as 'marginally food-secure'.

$\underline{\text { TBR3 }}$

Scoring of the food security scales: 18 -item module and 6-item short form

\begin{tabular}{|c|c|c|c|}
\hline \multirow[b]{2}{*}{ Food security level } & \multicolumn{3}{|c|}{ Number of affirmative responses* } \\
\hline & $\begin{array}{c}\text { 18-item, households with } \\
\text { children }\end{array}$ & $\begin{array}{l}\text { 18-item, households } \\
\text { without children (10 } \\
\text { used) }\end{array}$ & $\begin{array}{c}\text { 6-item short form, all } \\
\text { households }\end{array}$ \\
\hline Food-secure & 0 & 0 & 0 \\
\hline Food-secure, at risk & $1-2$ & $1-2$ & 1 \\
\hline $\begin{array}{l}\text { Food-insecure } \\
\text { without hunger }\end{array}$ & $3-7$ & $3-5$ & $2-4$ \\
\hline $\begin{array}{l}\text { Food-insecure, } \\
\text { moderate hunger }\end{array}$ & $8-12$ & $6-8$ & $5-6 \dagger$ \\
\hline $\begin{array}{l}\text { Food-insecure, } \\
\text { severe hunger }\end{array}$ & $13-18$ & $9-10$ & \\
\hline
\end{tabular}

\section{Why use the US Household Food Security Module?}

Table 2 displays the components of food insecurity $\underline{B} 10 \mathrm{~B} 11 \mathrm{~B} 1210-13$ and identifies the scale items corresponding to that component. As can be seen, to ensure coverage of the various components of food insecurity, and to include severe levels of hunger, it is important to include all 18 items to measure food insecurity and hunger comprehensively. Some researchers have chosen a smaller set of items, or have modified items, based upon a desire for fewer questions or assumed face validity. Such measures may not assess food insecurity comprehensively, and using different items or a unique set of items makes it difficult or impossible to compare results with the national measure, which is derived each year from the CPS. In addition, the full module is being used in numerous other national and sub-national surveys, including the Survey of Program Dynamics, The Early Childhood Longitudinal Survey, the Panel Survey of Income Dynamics, NHANES beginning with NHANES 99, and a study by the Rhode Island Department of Health. Use of the full 18-item module allows comparison with such studies.

\section{The 6-item short form of the module}

For surveys that cannot include 18 items, even with the understanding that a very small percentage of households are asked all 18 items, a 6-item short form has been developed using statistical methods to select a scale with the optimum sensitivity and specificity as well as conceptual validity $\underline{21}$. The items 
included in the short form of the module are numbered in bold in TBR1 Tables 1 and 2. Use of this short form is recommended rather than selecting an idiosyncratic set of items from the 18 , as the short form has a known statistical association with the full module, and prevalence rates can thus be adjusted to be comparable with rates from the full module. However, this module has several limitations. It does not measure all aspects of food insecurity. It contains no items referring specifically to children, and thus cannot provide data specific to children. It does not measure the more severe levels of hunger, and thus categorises households only as food-secure, food-insecure without hunger and food-secure with hunger, with no further breakdown for moderate or severe hunger.

\section{Food insecurity and food insufficiency measurement}

Since the late 1970s, the UDSA Food Sufficiency Indicator, initially used in the Current Survey of Food Intake in Individuals, has been used in numerous surveys. Administration of the indicator has varied, with some surveys using a four-part response, some using a three-part response, and some of the latter following up with a second question. The three variations are listed in Table 4. Many of the analyses of hunger or 'food insecurity' that have been done to date have used the food sufficiency indicator, since it has been included on surveys that also measure health, diet and economic factors. This indicator has also been used as a screen for the food security module, screening out households answering that they have enough food.

$\underline{\text { TBR4 }}$

Variations of the USDA Food Sufficiency Indicator

Single question, four-part response:

Which of these statements best describes the food eaten in your household?

Enough of the kinds of food you want to eat?

Enough but not always the kinds of food you want to eat?

Sometimes not enough to eat?

Often not enough to eat?

Single question, three-part response:

Which of the following statements best describes the food eaten in your household?

Enough food you want to eat?

Sometimes not enough to eat?

Often not enough to eat?

Two-question version:

Which of these statements best describes the amount of food eaten in your household? 
Enough food to eat?

Sometimes not enough to eat?

Often not enough to eat?

If the respondent answers 'Enough food to eat', s/he is asked:

Do you have enough of the kinds of food you want to eat? or

Do you have enough but not always the kinds of food you want to eat?

Because of its historical and analytical use, comparison of the food sufficiency indicator with the food security module is helpful. The food sufficiency indicator contains no time referent, while the food security scale refers to the past 12 months. Assuming that response to the food sufficiency indicator relates to the household's current situation, it is possible that food insecurity experienced earlier in the year may be omitted in answering the indicator. This is one problem with using this indicator as a screen.

Preliminary analyses at the ERS of the USDA, using data from the 1995 CPS, have shown that about half of respondents who answer that they 'sometimes' or 'often' do not have enough food to eat (USDA indicator) are classified as 'food-insecure with hunger'; while about $2 / 5$ of respondents who are classified as 'food-insecure with hunger' answer that they 'sometimes' or 'often' do not have enough to eat. The four-part response to the food sufficiency indicator underestimates moderate hunger and overestimates severe hunger, but fairly accurately estimates food insecurity (using responses of sometimes not enough, often not enough and enough but not the kinds we want combined); while the two-question version overestimates both hunger and food insecurity (personal communication, Mark Nord, ERS, USDA, 2000).

\section{Food security measurement in New Zealand, Australia and Canada}

The National Nutrition Survey of New Zealand, conducted in 1996-97, included eight items regarding food security $\underline{22}$. These were developed by Reid, who reviewed the CCHIP and Radimer/Cornell work and undertook qualitative research with New Zealand's indigenous populations $\underline{23}$. The eight items, shown in Table 5, included many of the components of food insecurity identified in the USA - food depletion, food anxiety and intake quantity - as well as coping tactics. However, food anxiety also included the importance of having food to share on special social occasions, which was particularly important in these cultures.

$\underline{\text { TBR5 }}$

Food insecurity item used in the National Nutrition Survey of New Zealand 


\begin{tabular}{|l|r|}
\hline 2. & Food runs out in my/our household due to lack of money. \\
\hline 3. & I/We eat less because of lack of money. \\
\hline 5. & $\begin{array}{r}\text { I/We rely on others to provide food and/or money for food, for my/our household when I/we do not } \\
\text { have enough money. }\end{array}$ \\
\hline 6. & I/We make use of special food grants or food banks when I/we do not have enough money for food. \\
\hline 7. & I feel stressed because of not having enough money for food. \\
\hline 8. & I feel stressed because I cannot provide the food I want for social occasions. \\
\hline
\end{tabular}

In 1993, a health survey undertaken in the state of Queensland, Australia included two questions adapted from the Radimer/Cornell measure. These were: (1) In the last 12 months, were there times that your household ran out of food and there was not money to buy any more food? and (2) In the last 12 months, has anyone in your household eaten less than they should because you could not afford more food? $\underline{24}$ Thus, one item assessed food depletion and the other inadequate quantity of intake. The Australian National Nutrition Survey, undertaken in 1995-96, and the Population Survey Monitor, conducted by the Australian Bureau of Statistics in August 1995 and February 1996, all contained an adaptation of the first question: In the last 12 months, were there any times you ran out of food and could not afford to buy any more? $\underline{25}$

Canada's National Population Health Survey, conducted in 1998-99, classified respondents as foodinsecure if they agreed that, over the past 12 months, they worried there would not be enough to eat because of lack of money; were not eating the quality or variety of foods they wanted to because of a lack of money; or did not have enough food to eat because of a lack of money (personal communication, Debra Reid, Ottawa-Carleton Health Department, 2000).

\section{Current issues in food security measurement in the USA}

While huge strides have been made in the measurement of food security, a number of issues concern people working in the field. Some issues are currently being addressed and some remain to be. These include: the assessment of food insecurity and hunger specifically in children; individual food security and hunger (the current measure inquires only about the household); translation of the core module into other languages; the validity of the instrument in various cultures in the way in which components of food security are ordered and expressed; the ability of the instrument to adequately capture severe but relatively short-term hunger; and the applicability of the components of food security and the instrument outside the United States.

\section{References}


[R1] Slater MD (1981) Going hungry on food stamps. Soc. Policy 11(4), 18-24.

[R2] (1993) In . pp Washington, DC: US Conference of Mayors.

[R3] Bishop KP (1983) In . pp Washington, DC: Center on Budget and Policy Priorities.

[R4] (1984) In . pp Boston, MA: Harvard University, School of Public Health.

[R5] (1985) In . pp Boston, MA: Harvard University, School of Public Health.

[R6] (1986) In . pp Boston, MA: Harvard University, School of Public Health.

[R7] (1984) In . pp Washington, DC: FRAC.

[R8] (1983) In . pp Washington, DC: Center on Budget and Policy Priorities.

[R9] (1984) In · pp Washington, DC: Government Printing Office.

[R10] Radimer KL, Olson CM \& Campbell CC (1990) Development of indicators to assess hunger. $J$. Nutr. 120, 1544-8.

[R11] Radimer KL, Olson CM, Green JC, Campbell CC \& Habicht J-P (1992) Understanding hunger and developing indicators to assess it in women and children. J. Nutr. Educ. 24, 36s-45s.

[R12] Radimer KL. Understanding hunger and developing indicators to assess it. $\mathrm{PhD}$ dissertation, Cornell University, Ithaca, NY, 1990

[R13] Anderson SA, ed. Core indicators of nutritional state for difficult-to-sample populations. J. Nutr. 1990; 120: 1559-99

[R14] Margen S \& Neuhauser LA (1987) In . pp Berkeley, CA: University of California-Berkeley, School of Public Health.

[R15] (1991) In . pp Washington, DC: FRAC.

[R16] Frongillo EA Jr, Rauschenbach BS, Olson CM, Kendall A \& Colmenares AG (1997) Questionnaire-based measures are valid for the identification of rural households with hunger and food insecurity. J. Nutr. 127, 699-705.

[R17] Kendall A, Olson CM \& Frongillo EA Jr (1995) Validation of the Radimer/Cornell measures of hunger and food insecurity. J. Nutr. 125, 2793-801.

[R18] Hamilton WL, Cook JT, Thompson WW, Buron LF, Frongillo EA \& Olson CM (1997) In . Report prepared for the US Department of Agriculture, Food and Consumer Service, pp Cambridge, MA: Abt 
Associates.

[R19] Hamilton WL, Cook JT, Thompson WW, Buron LF, Frongillo EA \& Olson CM (1997) In . Report prepared for the US Department of Agriculture, Food and Consumer Service, pp Cambridge, MA: Abt Associates.

[R20] Carlson SJ, Andrews MS \& Bickel GW (1999) Measuring food insecurity and hunger in the United States: development of a national benchmark measure and prevalence estimates. J. Nutr. 129, 510s-6s.

[R21] Blumberg SJ, Bialostosky K, Hamilton WL \& Briefel RR (1999) The effectiveness of a short form of the Household Food Security Scale. Am. J. Public Health 89, 1231-4.

[R22] Quigley R \& Watts C (1997) In . pp Wellington, New Zealand: Ministry of Health.

[R23] Reid J. Developing food security indicators for New Zealand. Master's thesis, University of Otago, Otago, New Zealand, 1997

[R24] Radimer KL, Allsopp R, Harvey PWJ, Firman DW \& Watson EK (1997) Food Insufficiency in Queensland. Aust. N.Z. J. Public Health 21, 303-10.

[R25] Radimer K (1996) Assessing food insecurity in industrialized countries. Proc. Nutr. Soc. N.Z. 21, 68-75.

\section{Footnotes:}

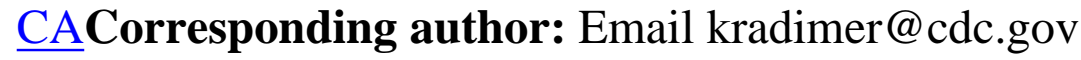

$\underline{\text { Top }}$ 